\title{
A review of the epidemiology and surveillance of viral zoonotic encephalitis and the impact on human health in Australia
}

\author{
Beverley J. Paterson ${ }^{\mathrm{A}, \mathrm{E}}$, John S. Mackenzie ${ }^{\mathrm{B}, \mathrm{C}}$, \\ David N. Durrheim ${ }^{\mathrm{A}}$ and David Smith ${ }^{\mathrm{D}}$ \\ ${ }^{\mathrm{A}}$ School of Medicine and Public Health, Faculty of Health, \\ The University of Newcastle \\ ${ }^{\mathrm{B}}$ Faculty of Health Sciences, Curtin University \\ ${ }^{\mathrm{C}}$ The Burnet Institute, Melbourne \\ ${ }^{\mathrm{D}}$ Division of Microbiology and Infectious Diseases, Western \\ Australian Centre for Pathology and Medical Research \\ ${ }^{\mathrm{E}}$ Corresponding author.Email: beverley.paterson@hnehealth. \\ nsw.gov.au
}

\begin{abstract}
Human encephalitis in Australia causes substantial mortality and morbidity, with frequent severe neurological sequelae and long-term cognitive impairment. This review discusses a number of highly pathogenic zoonotic viruses which have recently emerged in Australia, including Hendra virus and Australian bat lyssavirus which present with an encephalitic syndrome in humans. Encephalitis surveillance currently focuses on animals at sentinel sites and animal disease or definitive diagnosis of notifiable conditions that may present with encephalitis. This is inadequate for detecting newly emerged viral encephalatides. Hospital-based sentinel surveillance may aid in identifying increases in known pathogens or emergence of new pathogens that require a prompt public health response.
\end{abstract}

Human encephalitis causes substantial morbidity and mortality in Australia, frequently resulting in severe neurological sequelae and long-term cognitive impairment. While herpes simplex virus is the most commonly identified causative pathogen, the majority of adult encephalitis hospitalisations $(70 \%$, range $62-79 \%$ ) have no specific pathogen identified ${ }^{1}$ and an increasing proportion of encephalitis deaths are due to 'unknown' causes - from 47\% between 1979 and 1992 to 57\% between 1993 and $2006 .{ }^{2}$ Recently emerged or resurging pathogens in Australia, including Murray Valley encephalitis virus, West Nile virus (Kunjin clade), Japanese encephalitis virus, Hendra virus and Australian bat lyssavirus, cause a human encephalitis syndrome; consequently, encephalitis surveillance may be useful for signalling the emergence of novel infectious diseases, particularly viral zoonoses that may impact on human health.

Emerging infectious diseases pose a substantial threat in Australia and globally due to increased urbanisation, climate change, new farming practices, virus re-assortment and changes in human behaviours. ${ }^{3-5}$ The close interaction between animals and humans has provided opportunities for viruses to jump between species with $60 \%$ of known human infectious diseases and $75 \%$ of emerging infectious diseases being of animal origin. ${ }^{5,6}$ A One Health approach, which recognises the interdependence of human and animal health and the environment, is required to improve the surveillance of and response to Australian emerging infectious diseases.

\section{Surveillance for viral zoonotic encephalitis}

Surveillance for human viral zoonotic encephalitis in Australia depends on four different systems: notifications of specific infections to state and Commonwealth governments under public health legislation; serological surveillance of sentinel animals for flaviviruses; confirmatory testing of bats submitted after human contact for Australian bat lyssavirus; and mosquito surveillance for flaviviruses.

Although the encephalitis syndrome per se is not notifiable in Australia, specific diagnosis of a number of viral zoonotic encephalitides (Murray Valley encephalitis virus, West Nile virus (Kunjin clade), Japanese encephalitis virus, other flavivirus encephalitides and Australian bat lyssavirus) are notifiable by all states and territories, using common case definitions, to the Australian Government Department of Health and Ageing National Notifiable Diseases Surveillance System. ${ }^{7}$ Human Hendra virus infection is only notifiable in Queensland, although equine infections have occurred in both Queensland and northern New South Wales (NSW). ${ }^{8}$ Unfortunately, mandatory notification does not guarantee comprehensive reporting as it is based on detection of a causative organism. Therefore encephalitis due to rare or emerging pathogens may go unrecognised, which has led to proposals for systematic surveillance of the encephalitis syndrome., 


\section{Zoonotic encephalitis viruses}

Zoonotic encephalitis viruses fall into two groups, each with their own particular wildlife hosts, transmission mechanisms and ecologies. The first are the vectorborne and transmitted flaviviruses: Japanese encephalitis virus, Murray Valley encephalitis virus and West Nile virus (Kunjin clade). The second are the batborne viruses where bats act as the reservoir host: Hendra virus and Australian bat lyssavirus.

\section{Vectorborne flaviviruses}

The three flaviviruses Japanese encephalitis virus, Murray Valley encephalitis virus and West Nile virus (Kunjin clade) are closely related members of the Japanese encephalitis serological complex. Their maintenance hosts are ardeid waterbirds and their vectors are Culex spp. mosquitoes.

\section{Japanese encephalitis virus (JEV)}

JEV is the major cause of childhood viral encephalitis and associated disability in Asia. ${ }^{10,11}$ Only 1:25-1:300 infections result in clinical disease ${ }^{12,13}$ but $25 \%$ of clinical cases are fatal and $50 \%$ of affected humans experience neurological sequelae. Transmission cycles involve Culex spp. mosquitoes (especially Cx. tritaeniorhynchus), ardeid birds, such as black-crowned night herons (Nycticorax nycticorax), and pigs as vertebrate amplifying hosts. ${ }^{14}$ Humans become infected by a bite from an infected mosquito but they are incidental, dead-end hosts. It is worth noting that JEV also causes encephalitis in horses, and they too are incidental, dead-end hosts.

JEV emerged unexpectedly in the Torres Strait in 1995 (probably following importation from Papua New Guinea), causing three human cases of encephalitis in Badu, two of whom died. A further case occurred in Badu in 1998, as well as the first human JEV case on mainland Australia near the mouth of the Mitchell River, Cape York. ${ }^{15}$ Virus activity has been detected in the Torres Strait in almost all years since 1995, and in Cape York on the Australian mainland in 1998 and 2004.

Sentinel pig herds were kept on various Torres Strait islands and locations in northern Cape York for serological surveillance but, as these sites were usually close to human habitation and pigs are major virus amplifiers, the sentinel pig program was discontinued except for a single site on Cape York. Sporadic opportunistic mosquito collections are made by Queensland Health for virus isolation. Future JEV activity surveillance may be incorporated in the National Arbovirus Monitoring Program of Animal Health Australia, as cattle are safe animals for surveillance. ${ }^{16}$

A safe and effective inactivated, cell culture propagated JEV vaccine is available for those living or travelling in endemic areas, ${ }^{17}$ and several newer vaccines with potentially greater efficacy and safety are undergoing clinical trial.

\section{Murray Valley encephalitis virus (MVEV)}

Encephalitis outbreaks due to MVEV were first detected on Australia's east coast in the early 20th century, and then re-emerged as epidemics in the Murray-Darling River basin in 1951 and $1974 .{ }^{18}$ MVEV is now considered enzootic in the Kimberley and possibly the adjacent areas of the Northern Territory. The virus is maintained in a cycle primarily involving $C x$. annulirostris and ardeid waterbirds, and variable activity occurs every year in these areas. ${ }^{18}$ Virus activity outside these enzootic areas generally follows heavy rainfall and flooding within normally arid areas of northern and central Australia, as infected waterbirds migrate across the flooded areas. ${ }^{19,20}$ This may explain the reappearance of MVEV encephalitis in central Australia and western NSW in $2000-2001 .^{21}$ It now appears that low level MVEV activity may occur occasionally in NSW, and may have resulted in a locally acquired human infection in 2008. ${ }^{22}$ MVEV throughout Australia is predominantly genetically homogeneous, consistent with a single major enzootic source. ${ }^{23,24}$

Clinical MVEV encephalitis cases are uncommon in Australia with an average of 2-3 cases each year since the late 1970s. The incubation period ranges from 1 day to 4 weeks, and most infections are either asymptomatic or the patient only develops a self-limiting febrile illness with or without headache. Encephalitis occurs in only 1:500-1:1000 infected individuals with a mortality rate of $20 \%$; about half of all survivors have significant residual neurological deficits, with worse outcomes in the very young and elderly.

Infection risk depends on the degree of mosquito exposure during a period of MVEV activity. Generally, all residents and travellers are susceptible, with cases in all ages, except amongst Indigenous communities where there is regular virus activity, with infection more likely in young Indigenous children due to protective immunity in older children and adults. ${ }^{25,26}$

Currently, there is neither a vaccine nor any specific antiviral therapy for MVEV. Sero-surveillance is carried out using sentinel chicken flocks in Western Australia, the Northern Territory, NSW and Victoria, ${ }^{27}$ and by opportunistic mosquito sampling for virus isolation.

\section{West Nile virus (Kunjin clade) (WNV-KUN)}

WNV-KUN was first detected in northern Queensland in 1960 and is widely dispersed across tropical northern Queensland, the Northern Territory and Western Australia, being maintained in enzootic cycles similar to MVEV between Culex spp. mosquitoes and ardeid waterbirds. WNV-KUN activity is regularly detected in south-eastern Australia, but usually without recognised human cases. 
WNV-KUN is believed to have caused $11 \%$ of encephalitis cases in the 1974 Murray Valley outbreak. ${ }^{28}$ During the following three decades, three encephalitis cases caused by WNV-KUN were reported (all non-fatal), while $68 \mathrm{MVEV}$ encephalitis cases were confirmed. The incubation period appears similar to MVEV infection but the encephalitic illness is more benign with complete or near complete recovery. ${ }^{29}$

Currently, there is neither a vaccine nor any specific antiviral therapy for WNV-KUN infection. MVEV sentinel chicken flocks are also tested for WNV-KUN infection.

\section{Batborne viruses \\ Hendra virus ( $\mathrm{HeV}$ )}

$\mathrm{HeV}$ was first described in 1994 during an outbreak of severe respiratory disease amongst racehorses and humans in Brisbane. ${ }^{30,31}$ A second outbreak occurred at the same time but was unrecognised for a further 13 months. A Mackay farmer, infected while assisting with an equine autopsy, suffered mild meningitis and recovered, but 13 months later relapsed with fatal encephalitis. ${ }^{32}$ There have been 12 further outbreaks; ${ }^{33,34} 11$ in Queensland and one near Murwillumbah in NSW. There have been seven confirmed human $\mathrm{HeV}$ infections, with four deaths. Flying foxes of the genus Pteropus are the reservoir host,${ }^{35}$ but all human infections to date have been epidemiologically linked to horses, the major spill-over host. Horses are believed to become infected after grazing on pastures contaminated with bat urine, birthing fluids or spats (fibrous plant material remaining after mastication by bats). Humans become infected by the virus entering through cuts or grazes after exposure to equine bodily fluids, but humans are dead-end hosts and there is no evidence of human-to-human infection.

$\mathrm{HeV}$ is one of two members of the genus Henipavirus, the other being Nipah virus, the cause of fatal encephalitis affecting pigs and humans in Malaysia in $1999 .{ }^{33}$ Nipah virus, like $\mathrm{HeV}$, is a virus of Pteropid bats, but with pigs as the spill-over hosts. Very recent studies have indicated that pigs could also potentially act as spill-over hosts for $\mathrm{HeV} .{ }^{36}$ Human-to-human transmission with Nipah virus resulting in cases of clinical disease has been documented, with some of the cases probably being due to ingestion of bat-contaminated palm juice, whereas others may be due to other routes of infection. ${ }^{33,37}$ Human-to-human transmission of $\mathrm{HeV}$ has not been reported. Over the past decade, sero-epidemiological studies have shown that $\mathrm{HeV}$ and Nipah virus, or closely related viruses, are widely distributed over the range of Pteropid bats. ${ }^{3,34,38}$

There is no active surveillance for $\mathrm{HeV}$ in Australia, in either humans or animals, and spill-over infections are uncovered when there is clinical evidence of infection in horses. Veterinarians and others likely to be exposed to infected bats or horses should take appropriate personal protection measures. It is not practical to prevent all interactions between flying foxes and horses, and no vaccines are available, although post-exposure prophylaxis is currently being investigated and shows promise.

\section{Australian bat lyssavirus (ABLV)}

ABLV was first isolated in 1996 in NSW from the brain of a black flying fox (Pteropus alecto) which was behaving strangely ${ }^{39}$ It is closely related to rabies virus, ${ }^{40}$ but is distinguishable genetically and thus classified as lyssavirus serotype 1, genotype 7. ${ }^{34,41}$ ABLV has been found in all four species of Australian flying fox (genus Pteropus) throughout their geographic range, and in at least one species of insectivorous microbat, the yellow-bellied sheath-tailed bat (Saccolaimus flaviventris), in Queensland. ${ }^{34,42}$ Serological evidence of infection has also been found in a number of other genera, and the ecology and diversity of this virus is yet to be fully understood. Less than $1 \%$ of flying foxes in the wild are infected with ABLV, but this increases to as many as $15 \%$ of sick or injured flying foxes and about 3\% of yellow-bellied sheath-tailed bats. ${ }^{43}$ Limited studies to infect terrestrial wildlife have failed, although experimental exposure of domestic cats and dogs can produce mild signs and seroconversion but with no evidence of viral persistence. ${ }^{44}$

ABLV has caused two human deaths in Australia. The first was a bat carer who had been scratched by a yellow-bellied sheath-tailed bat 5 weeks earlier ${ }^{45,46}$ and the second, a woman bitten 2 years prior by a flying fox. ${ }^{47}$ In both patients the disease was similar to classical rabies, with non-suppurative encephalitis accompanied by hypersalivation, aggression and agitation. Currently available cellculture derived vaccines appear efficacious in protecting against ABLV infection in exposed humans. ${ }^{48,49}$ Bat carers and others at risk of ABLV exposure are offered preexposure vaccination and those exposed are given standard preparations of vaccine and the rabies immune globulin. ${ }^{17,43}$ It is important that, wherever possible, the bat responsible for the potential exposure is sent for testing.

\section{Discussion}

Globally, many of the recently emerged Australian zoonotic viruses have presented with an encephalitic syndrome in humans, ${ }^{6,50}$ including the highly pathogenic $\mathrm{HeV}$ and $\mathrm{ABLV} .^{51,52}$ Other zoonotic viral encephalitides have appeared in new Australian regions, including JEV, MVEV and WNV-KUN. ${ }^{53}$ Current Australian surveillance, which focuses on seroconversion in sentinel animals in a limited number of sentinel sites (pigs for JEV and chickens for MVEV and WNV-KUN), definitive diagnosis in reservoir hosts (culled bats that have had potential transmission contact with humans for ABLV or horses for $\mathrm{HeV}$ ), or definitive diagnosis in humans, has the 
potential to miss encephalitis cases caused by notifiable conditions, and is particularly inadequate for detecting newly emerged viral encephalitides. ${ }^{2}$ A recent study examining the diagnostic assessment of encephalitis in three Regional Referral Hospitals in NSW determined that only $15 \%$ of encephalitis patients were tested for flaviviruses and $0-7 \%$ were tested for specific zoonotic encephalitis viruses. ${ }^{54}$

\section{Conclusion}

Given that viral encephalitis generally causes relatively serious illness resulting in hospitalisation, ${ }^{55}$ the utility of hospital sentinel surveillance of adults or paediatric medicine inpatients deserves prompt investigation, as does the use of a standardised diagnostic and testing algorithm which includes viral zoonotic encephalitides. Improvements in encephalitis surveillance at the animal, human, environment interface would aid in earlier identification of known pathogens and in alerting authorities to the emergence of new pathogens or outbreaks that may require public health investigation and action.

\section{Editor's note}

During 2011 there has been a resurgence in MVE across Australian states with 14 confirmed cases notified in the National Notifiable Diseases Surveillance System, including one in NSW, and two deaths. Canadian authorities also confirmed the additional death of a Canadian tourist who was infected in the Northern Territory. ${ }^{56-59}$

\section{References}

1. Huppatz C, Durrheim DN, Levi C, Dalton C, Williams D, Clements MS et al. Etiology of encephalitis in Australia, 1990-2007. Emerg Infect Dis 2009; 15(9): 1359-65. doi:10.3201/eid1509.081540

2. Huppatz C, Kelly PM, Levi C, Dalton C, Williams D, Durrheim DN. Encephalitis in Australia, 1979-2006: trends and aetiologies. Commun Dis Intell 2009; 33(2): 192-7.

3. Morens DM, Folkers GK, Fauci AS. The challenge of emerging and re-emerging infectious diseases. Nature 2004; 430(6996): 242-9. doi:10.1038/nature02759

4. Morse SS. The public health threat of emerging viral disease. J Nutr 1997; 127(5, Suppl): 951S-7S.

5. Organisation Mondiale de la Sante Animale. One world, one health 2009.

6. Jones KE, Patel NG, Levy MA, Storeygard A, Balk D, Gittleman JL et al. Global trends in emerging infectious diseases. Nature 2008; 451(7181): 990-3. doi:10.1038/nature06536

7. Australian Government Department of Health and Ageing. Arbovirus and malaria surveillance. Available from: http:// www.health.gov.au/arbovirus (Cited 9 September 2010.)

8. Hess IMR, Massey PD, Walker B, Middleton DJ, Wright TM. Hendra virus: what do we know? NS W Public Health Bull 2011; 22(5-6): 118-22. doi:10.1071/NB10077
9. Trevejo RT. Acute encephalitis hospitalizations, California, 1990-1999: unrecognized arboviral encephalitis? Emerg Infect Dis 2004; 10(8): 1442-9.

10. Halstead SB, Jacobson J. Japanese encephalitis. Adv Virus Res 2003; 61: 103-38. doi:10.1016/S0065-3527(03)61003-1

11. Mackenzie JS, Williams DT, Smith DW. Japanese encephalitis virus: the geographic distribution, incidence, and spread of a virus with a propensity to emerge in new areas. In: Tabor E, editor. Emerging viruses in human populations. Amsterdam: Elsevier; 2007. pp. 201-68.

12. Burke DS, Leake CJ. Japanese encephalitis. In: Monarth TP, editor. The arboviruses: Epidemiology and Ecology. Boca Raton: CRC Press; 1988. pp. 63-92.

13. Vaughn DW, Hoke CH, Jr. The epidemiology of Japanese encephalitis: prospects for prevention. Epidemiol Rev 1992; 14: 197-221.

14. Endy TP, Nisalak A. Japanese encephalitis virus: ecology and epidemiology. Curr Top Microbiol Immunol 2002; 267: 11-48.

15. Mackenzie JS, Johansen CA, Ritchie SA, van den Hurk AF, Hall RA. Japanese encephalitis as an emerging virus: the emergence and spread of Japanese encephalitis virus in Australasia. Curr Top Microbiol Immunol 2002; 267: 49-73.

16. Peiris JS, Amerasinghe FP, Arunagiri CK, Perera LP, Karunaratne SH, Ratnayake CB et al. Japanese encephalitis in Sri Lanka: comparison of vector and virus ecology in different agro-climatic areas. Trans $R$ Soc Trop Med Hyg 1993; 87(5): 541-8. doi:10.1016/0035-9203(93)90080-A

17. National Health and Medical Research Council. The Australian Immunisation Handbook. 9th ed. 2008. Available from: http:// www.health.gov.au/internet/immunise/publishing.nsf/Content/ Handbook-japanese (Cited 14 September 2010.)

18. Mackenzie JS, Lindsay MD, Coelen RJ, Broom AK, Hall RA, Smith DW. Arboviruses causing human disease in the Australasian zoogeographic region. Arch Virol 1994; 136(3-4): 447-67. doi:10.1007/BF01321074

19. Broom AK, Lindsay MD, Plant AJ, Wright AE, Condon RJ, Mackenzie JS. Epizootic activity of Murray Valley encephalitis virus in an aboriginal community in the southeast Kimberley region of Western Australia: results of cross-sectional and longitudinal serologic studies. Am J Trop Med Hyg 2002; 67(3): 319-23.

20. Cordova SP, Smith DW, Broom AK, Lindsay MD, Dowse GK, Beers MY. Murray Valley encephalitis in Western Australia in 2000, with evidence of southerly spread. Commun Dis Intell 2000; 24(12): 368-72.

21. Brown A, Bolisetty S, Whelan P, Smith D, Wheaton G. Reappearance of human cases due to Murray Valley encephalitis virus and Kunjin virus in central Australia after an absence of 26 years. Commun Dis Intell 2002; 26(1): 39-44.

22. Evans IA, Hueston L, Doggett SL. Murray Valley encephalitis virus. N S W Public Health Bull 2009; 20(11-12): 195-6. doi:10.1071/NB09022

23. Johansen CA, Susai V, Hall RA, Mackenzie JS, Clark DC, May FJ et al. Genetic and phenotypic differences between isolates of Murray Valley encephalitis virus in Western Australia, 1972-2003. Virus Genes 2007; 35(2): 147-54. doi:10.1007/ s11262-007-0091-2

24. Mackenzie JS, Poidinger M, Lindsay MD, Hall RA, Sammels LM. Molecular epidemiology and evolution of mosquito-borne 
flaviviruses and alphaviruses enzootic in Australia. Virus Genes 1995; 11(2-3): 225-37. doi:10.1007/BF01728662

25. Broom AK, Lindsay MD, Harrington SA, Smith DW. Investigation of the southern limits of Murray Valley encephalitis activity in Western Australia during the 2000 wet season. Vector Borne Zoonotic Dis 2002; 2: 87-95. doi:10.1089/153036602321131887

26. Smith DW, Broom AK, Wallace MJ. Prevalence of antibody to Murray Valley encephalitis virus in Aboriginal communities in the Kimberley region of Western Australia in 1995. Arbovirus Research in Australia 1997; 7.

27. Spencer JD, Azoulas J, Broom AK, Buick TD, Currie B, Daniels PW et al. Murray Valley encephalitis virus surveillance and control initiatives in Australia. National Arbovirus Advisory Committee of the Communicable Diseases Network Australia. Commun Dis Intell 2001; 25(2): 33-47.

28. Doherty RL, Carley JG, Filippich C, White J, Gust ID. Murray Valley encephalitis in Australia, 1974: antibody response in cases and community. Aust N Z J Med 1976; 6(5): 446-53. doi:10.1111/j.1445-5994.1976.tb03033.x

29. Hall RA, Broom AK, Smith DW, Mackenzie JS. The ecology and epidemiology of Kunjin virus. Curr Top Microbiol Immunol 2002; 267: 253-69.

30. Murray K, Selleck P, Hooper P, Hyatt A, Gould A, Gleeson L et al. A morbillivirus that caused fatal disease in horses and humans. Science 1995; 268(5207): 94-7. doi:10.1126/ science. 7701348

31. Selvey LA, Wells RM, McCormack JG, Ansford AJ, Murray K, Rogers RJ et al. Infection of humans and horses by a newly described morbillivirus. Med J Aust 1995; 162(12): 642-5.

32. O'Sullivan JD, Allworth AM, Paterson DL, Snow TM, Boots R, Gleeson LJ et al. Fatal encephalitis due to novel paramyxovirus transmitted from horses. Lancet 1997; 349(9045): 93-5. doi:10.1016/S0140-6736(96)06162-4

33. Eaton BT, Mackenzie JS, Wang LF. Henipaviruses. In: Knipe DM, Howley PM, editors. Fields Virology. 5th ed. Philadelphia: Lippincott Williams \& Wilkins; 2007. pp. 1587-600.

34. Mackenzie JS, Childs JE, Field HE, Wang LF, Breed AC. The role of bats as reservoir hosts of emerging neurological viruses. In: Reiss CS, editor. Neurotropic Viral Infections. Cambridge: Cambridge University Press; 2008. pp. 382-406.

35. Halpin K, Young PL, Field HE, Mackenzie JS. Isolation of Hendra virus from pteropid bats: a natural reservoir of Hendra virus. J Gen Virol 2000; 81(Pt 8): 1927-32.

36. Li M, Embury-Hyatt C, Weingartl HM. Experimental inoculation study indicates swine as a potential host for Hendra virus. Vet Res 2010; 41(3): 33. doi:10.1051/vetres/2010005

37. Luby SP, Rahman M, Hossain MJ, Blum LS, Husain MM, Gurley E et al. Foodborne transmission of Nipah virus, Bangladesh. Emerg Infect Dis 2006; 12(12): 1888-94.

38. Hayman DT, Suu-Ire R, Breed AC, McEachern JA, Wang L, Wood JL et al. Evidence of henipavirus infection in West African fruit bats. PLOS ONE 2008; 3(7): e2739. doi:10.1371/ journal.pone. 0002739

39. Fraser GC, Hooper PT, Lunt RA, Gould AR, Gleeson LJ, Hyatt $\mathrm{AD}$ et al. Encephalitis caused by a Lyssavirus in fruit bats in Australia. Emerg Infect Dis 1996; 2(4): 327-31. doi:10.3201/ eid0204.960408
40. Gould AR, Hyatt AD, Lunt R, Kattenbelt JA, Hengstberger S, Blacksell SD. Characterisation of a novel lyssavirus isolated from Pteropid bats in Australia. Virus Res 1998; 54(2): 165-87. doi:10.1016/S0168-1702(98)00025-2

41. Delmas O, Holmes EC, Talbi C, Larrous F, Dacheux L, Bouchier $\mathrm{C}$ et al. Genomic diversity and evolution of the lyssaviruses. PLOS ONE 2008; 3(4): e2057. doi:10.1371/journal.pone. 0002057

42. Mackenzie JS, Field HE. Emerging encephalitogenic viruses: lyssaviruses and henipaviruses transmitted by frugivorous bats. Arch Virol Suppl 2004; (18): 97-111.

43. Ewald B, Durrheim D. Australian Bat Lyssavirus: examination of post-exposure treatment in NSW. NSW Public Health Bull 2008; 19(5-6): 104-7. doi:10.1071/NB07050

44. McColl KA, Chamberlain T, Lunt RA, Newberry KM, Westbury HA. Susceptibility of domestic dogs and cats to Australian bat lyssavirus (ABLV). Vet Microbiol 2007; 123(1-3): 15-25. doi:10.1016/j.vetmic.2007.03.024

45. Hooper P, Lunt R, Gould A, Samaratunga H, Hyatt A, Gleeson L. A new Lyssavirus: the first endemic rabies related virus recognised in Australia. Bull Inst Pasteur 1997; 95: 209-18. doi:10.1016/S0020-2452(97)83529-5

46. Allworth A, Murray K, Morgan J. A human case of encephalitis due to a lyssavirus recently identified in fruit bats. Commun Dis Intell 1996; 20: 504.

47. Hanna JN, Carney IK, Smith GA, Tannenberg AE, Deverill JE, Botha JA et al. Australian bat lyssavirus infection: a second human case, with a long incubation period. Med J Aust 2000; 172(12): 597-9.

48. Brookes SM, Parsons G, Johnson N, McElhinney LM, Fooks AR. Rabies human diploid cell vaccine elicits cross-neutralising and cross-protecting immune responses against European and Australian bat lyssaviruses. Vaccine 2005; 23(32): 4101-9. doi: $10.1016 /$ j.vaccine. 2005.03 .037

49. Rupprecht CE, Gibbons RV. Clinical practice. Prophylaxis against rabies. $N$ Engl J Med 2004; 351(25): 2626-35. doi:10.1056/NEJMcp042140

50. Weaver SC, Reisen WK. Present and future arboviral threats. Antiviral Res 2010; 85(2): 328-45. doi:10.1016/j.antiviral. 2009.10.008

51. Barclay AJ, Paton DJ. Hendra (equine morbillivirus). Vet J 2000; 160(3): 169-76. doi:10.1053/tvj1.2000.0508

52. Samaratunga H, Searle JW, Hudson N. Non-rabies Lyssavirus human encephalitis from fruit bats: Australian bat Lyssavirus (pteropid Lyssavirus) infection. Neuropathol Appl Neurobiol 1998; 24(4): 331-5. doi:10.1046/j.13652990.1998.00129.x

53. Mackenzie JS. Emerging zoonotic encephalitis viruses: lessons from Southeast Asia and Oceania. J Neurovirol 2005; 11(5): 434-40. doi:10.1080/13550280591002487

54. Huppatz C, Gawarikar Y, Levi C, Kelly PM, Williams D, Dalton $\mathrm{C}$ et al. Should there be a standardised approach to the diagnostic workup of suspected adult encephalitis? A case series from Australia. BMC Infect Dis 2010; 10: 353. doi:10.1186/14712334-10-353

55. Whitley RJ, Gnann JW. Viral encephalitis: familiar infections and emerging pathogens. Lancet 2002; 359(9305): 507-13. doi:10.1016/S0140-6736(02)07681-X 
56. Australian Government Department of Health and Ageing. National Notifiable Diseases Surveillance System. Available from: http://www9.health.gov.au/cda/source/CDA-index.cfm (Cited 15 June 2011.)

57. Government of Western Australia Department of Health. Mosquito-borne disease risk extends to south-central regions of WA. Media Release 16 May 2011. Available from: http://www. health.wa.gov.au/press/view_press.cfm?id=994 (Cited 15 June 2011.)
58. SA Health. Murray Valley encephalitis. Media Release, 3 May 2011. Available from: http://www.sahealth.sa.gov.au/wps/wcm/ connect/public + content/sa+health + internet/health + information/news/media + releases/murray + valley + encephalitis (Cited 15 June 2011.)

59. ProMED-mail. Murray Valley encephalitis - Australia (07): Canada ex Australia (Northern Territory). 26 May 2011. Archive 20110526.1610. Available from: http:www.promedmail.org (Cited 15 June 2011.)

\section{NSW Public Health Bulletin Subscription Form and Electronic Early Alert Service}

To subscribe to the hard copy of the NSW Public Health Bulletin or to change your subscription details please complete this form and return it by email (phbulletin@doh.health.nsw.gov.au) or fax (61 293919232 ).

The Bulletin can be accessed electronically from www.publish.csiro.au/journals/phb. Subscribe to the Early Alert service to be notified as soon as it appears online (www.publish.csiro.au/earlyalert).

\section{Subscription information}

I wish to receive the NSW Public Health Bulletin:

My details are as follows

Name:

Organisation:

Mailing Address:

State: Postcode: Country:

Telephone: Facsimile:

Email:.

\section{Change of Address}

I wish to change my mailing details, as follows:

Name:

From: [Insert old address]

To: [Insert new address] 